\title{
Cost Effectiveness of the Earned Income Tax Credit as a Health Policy Investment Babak Mohit, MBA, DrPH
}

\author{
Peter A. Muennig, MD, MPH, ${ }^{1}$ Babak Mohit, MPH, MBA, PhD, ${ }^{1}$ Jinjing Wu, PhD, ${ }^{1}$ Zohn Rosen, PhD, ${ }^{1}$ \\ Haomiao Jia, PhD $^{2}$
}

\begin{abstract}
Introduction: Lower-income Americans are suffering from declines in income, health, and longevity over time. Income and employment policies have been proposed as a potential nonmedical solution to this problem.
\end{abstract}

Methods: An interrupted time series analysis of state-level incremental supplements to the Earned Income Tax Credit (EITC) program was performed using data from 1993 to 2010 Behavioral Risk Factor Surveillance System surveys and state-level life expectancy. The cost effectiveness of state EITC supplements was estimated using a microsimulation model, which was run in 2015.

Results: Supplemental EITC programs increased health-related quality of life and longevity among the poor. The program costs about $\$ 7,786 /$ quality-adjusted life-year gained ( $95 \% \mathrm{CI}=\$ 4,100$, $\$ 13,400)$ for the average recipient. This ratio increases with larger family sizes, costing roughly $\$ 14,261$ (95\% CI $=\$ 8,735, \$ 19,716)$ for a family of three.

Conclusions: State supplements to EITC appear to be highly cost effective, but randomized trials are needed to confirm these findings.

(Am J Prev Med 2016;:I(I):III-nII) @ 2016 American Journal of Preventive Medicine. Published by Elsevier Inc. All rights reserved.

\section{Introduction}

$\mathrm{S}$ tarting in the 1990s, lower-income Americans began to realize a gradual decline in health, followed by a decline in life expectancy. ${ }^{1-5}$ This trend among lower-income Americans is historically unprecedented in a nation that is not confronting a catastrophe, such as the fall of the Soviet Union or the HIV/AIDS crisis in sub-Saharan Africa of the 1990s. ${ }^{6}$ In parallel with this trend, skyrocketing healthcare costs and declining wages have been eroding the standard of living among low- and middle-income households in the U.S. If these confluent health and macroeconomic stressors continue, the U.S. may be faced with a future in which the tide of increasing prosperity and health throughout much of the 20th century, for lower middle class Americans, slowly recedes.

From the ${ }^{1}$ Mailman School of Public Health, Columbia University, New York, New York; and ${ }^{2}$ School of Nursing. Columbia University, New York, New York

Address correspondence to: Peter A. Muennig, MD, MPH, Mailman School of Public Health, Columbia University, 722 West 168th St., ARB 4th Floor, New York NY 10032. E-mail: pm124@columbia.edu. 0749-3797/\$36.00

http://dx.doi.org/10.1016/j.amepre.2016.07.001
Poverty is believed to be a major risk factor for poor health. ${ }^{8,9}$ Poverty is independently associated with a larger burden of disease than obesity or smoking. ${ }^{10}$ It may therefore be possible to improve the health and increase the longevity of lower-income Americans with anti-poverty programs. ${ }^{11-13}$ Such programs can improve the standard of living of lower-income Americans, thereby reducing exposure to crime, stress, poor housing, and cheap processed foods. In this conceptualization, poverty is an "upstream" risk factor for an array of other risk factors that produce much of the disease and death in America. If poverty damages one's health, then antipoverty programs targeted toward younger, healthy workers might conceivably function as a primary prevention "vaccine" against a downward spiral of poverty and poor health. ${ }^{14-17}$

One social welfare program, the Earned Income Tax Credit (EITC), designed to boost both income and employment, has lifted 7 million Americans out of poverty and has received bipartisan support. ${ }^{18-20}$ Presently, 27 states supplement the federal program with their own "supplemental" EITC.

However, the association between EITC receipt and health or longevity has not been proven, the program is 
expensive, and there is some evidence that it might increase the BMI of some low-income Americans., ${ }^{921}$ There are proposals presently in Congress aimed at expanding EITC, particularly to childless workers, but these proposals have not yet been funded despite support by both parties. ${ }^{22}$ In this study, causal modeling of state EITC supplementation on health was therefore conducted and these data were entered into a microsimulation model to determine whether supplementation is a cost-effective way to improve population health.

\section{Methods}

\section{Overview}

These analyses are described in detail in the Appendix (available online), which includes additional introductory text, the date of implementation, magnitude of the EITC increase by state, doseresponse analyses, analyses by each state, further details of the methods, and additional results. ${ }^{23-25}$

To estimate the effect of state-level EITC supplementation on health, an interrupted time series difference-in-difference analysis of state-level mortality rates and health-related quality of life (HRQL) scores was conducted between 1980 and 2011. With the average change in HRQL and mortality rates across all states that supplemented EITC, it is possible to estimate the number of quality-adjusted life-years (QALYs, or years of life lived in perfect health). ${ }^{26}$ Note that EITC recipients are a high-risk population for premature mortality, and comprise upwards of one in ten people in each state. They are therefore responsible for a disproportionate share of annual mortality changes in a given state. Each outcome measure (HRQL and mortality rate) was estimated as the net, weighted mean effect across states that supplemented the federal EITC relative to before supplementation. The effect was also estimated relative to states that did not supplement over the period of interest-from 1980 to 2011. The analysis did not account for the magnitude of the supplement in individual states, but rather the binary effect (supplement or no supplement).

The effects by state and the effect by the size of the supplement were estimated in a secondary analysis. These estimates are associational, and therefore represent a weaker estimation approach (Appendix, available online). In theory, it is possible to account for these effects using an instrumental variable approach (yielding an estimate that is less subject to confounding), but the sample size was inadequate for such an analysis.

The cost of the EITC supplemental programs was evaluated using estimates of deadweight loss associated with tax transfers. ${ }^{27}$ In this case, deadweight loss is an estimate of economic inefficiency produced when tax dollars are used to supplement labor income. The cost-effectiveness analysis followed the recommendations of the Panel on Cost-Effectiveness in Health and Medicine, and employed a $3 \%$ rate of discount for future costs and QALYs gained. ${ }^{26}$ The model input parameters are presented in Table 1. The model assumed that deadweight loss was correctly estimated, that the interrupted time series (quasi-experimental) analyses of EITC implementation by state correctly estimated their health impacts, and that EITC did not impact other costs (e.g., health expenditures).
Table 1. Input Values for the Microsimulation Model and the Associated Range of Error

\begin{tabular}{|c|c|c|}
\hline Maximum return (\$) & Value & $\begin{array}{l}\text { High/low } \\
\text { (SE) }\end{array}$ \\
\hline \multicolumn{3}{|l|}{ Cost inputs } \\
\hline \multicolumn{3}{|l|}{ Earned income tax credit $^{a}$} \\
\hline Average & $\$ 2,440$ & \\
\hline 0 children & $\$ 496$ & - \\
\hline 1 child & $\$ 3,305$ & - \\
\hline 2 children & $\$ 5,460$ & - \\
\hline$\geq 3$ children & $\$ 6,143$ & - \\
\hline $\begin{array}{l}\text { Deadweight loss on } \\
\text { return }\end{array}$ & $30 \%$ & $15 \%, 45 \%$ \\
\hline \multicolumn{3}{|l|}{ Probability inputs } \\
\hline State life expectancy & $\begin{array}{l}\text { Annual, age- } \\
\text { specific }\end{array}$ & - \\
\hline \multicolumn{3}{|c|}{ Annual change in $\mathrm{QALE}^{\mathrm{b}}$} \\
\hline Average & 0.097 & 0.020 \\
\hline 0 children $^{c}$ & 0.069 & $-{ }^{c}$ \\
\hline 1 child $^{\circ}$ & 0.087 & $-^{\mathrm{c}}$ \\
\hline 2 children $^{c}$ & 0.097 & $-{ }^{c}$ \\
\hline$\geq 3$ children $^{c}$ & 0.126 & $-{ }^{c}$ \\
\hline
\end{tabular}

${ }^{\text {a }}$ The cost of the EITC by family size is calculated by multiplying the average returns by the deadweight loss ratio.

${ }^{\mathrm{b}}$ The annual change in QALE for recipients of EITC in states that expanded their EITC programs. The QALE is calculated using spatiotemporal differences in mapped EuroQol 5D (EQ5D) scores in states that did and did not expand EITC and is statistically significant at $p<0.0001$.

${ }^{\mathrm{C}}$ Annual variation in life expectancy by family size is not available at the state level. The annual QALE gained was estimated using linear interpolation of $\mathrm{HRQL}$ scores under the assumption that life expectancy is directly proportional to HRQL.

EITC, earned income tax credit; HRQL, health-related quality of life; QALE, quality-adjusted life expectancy.

\section{Mortality and Health-Related Quality of Life}

Two data sources were used to estimate the change in qualityadjusted life expectancy (QALE) associated with EITC expansion: (1) state-level Behavioral Risk Factor Surveillance System (BRFSS) data from 1993 to 2011 to obtain annual state-level age-adjusted HRQL and (2) the annual state-level age-adjusted mortality data from 1980 to 2011 from the Compressed Mortality File to calculate annual state-specific life expectancy. ${ }^{27-29}$ The models were run in November 2015. Responses to questions within the BRFSS were mapped to the EuroQol 5D (EQ-5D) index, an HRQL-compatible measure. ${ }^{29}$ QALE was then estimated by first estimating that statelevel mortality rate and mean EQ-5D index in each age group and then building life tables from these data. ${ }^{30-33}$

Because the BRFSS and the Compressed Mortality File cover different years of observation and contain different variables, the 
233 T10 different points in time (Table 2). Usable mortality data were 234 available for 26 states and usable HRQL data for 22 states.

Table 2. Supplemental EITC Benefit by State,
QALE Associated With Implementation of EITC

\begin{tabular}{|c|c|c|c|}
\hline State & $\begin{array}{c}\text { Year } \\
\text { enacted }\end{array}$ & $\begin{array}{c}\text { Intervention size } \\
\text { (\% addition to Federal EITC) }\end{array}$ & $\begin{array}{l}\text { Increase in } \\
\text { QALE }\end{array}$ \\
\hline California & 2015 & 85 & $-^{a}$ \\
\hline Colorado & 1999, 2013 & 10 & $--^{\mathrm{b}, \mathrm{c}}$ \\
\hline Connecticut & 2011 & 27.5 & $-{ }^{\mathrm{b}}$ \\
\hline Delaware & 2005 & 20 & -0.017 \\
\hline District of Columbia & 2000 & 40 & -0.057 \\
\hline Illinois & 2000 & 10 & 0.261 \\
\hline Indiana & 1999 & 9 & 0.045 \\
\hline lowa & 1989 & 15 & 0.117 \\
\hline Kansas & 1998 & 17 & 0.054 \\
\hline Louisiana & 2007 & 3.5 & 0.049 \\
\hline Maine & 2000 & 5 & -0.016 \\
\hline Maryland & 1987 & 25.5 & 0.029 \\
\hline Massachusetts & 1997 & 23 & 0.070 \\
\hline Michigan & 2006 & 6 & 0.398 \\
\hline Minnesota & 1991 & 35 & 0.114 \\
\hline Nebraska & 2006 & 10 & 0.247 \\
\hline New Jersey & 2000 & 30 & 0.008 \\
\hline New Mexico & 2007 & 10 & 0.150 \\
\hline New York & 1994 & 30 & 0.227 \\
\hline Ohio & 2013 & 10 & $--^{\mathrm{b}}$ \\
\hline Oklahoma & 2002 & 5 & 0.807 \\
\hline Oregon & 1997 & 8 & -0.096 \\
\hline Rhode Island & 1986 & 12.5 & 0.062 \\
\hline Vermont & 1988 & 32 & 0.090 \\
\hline Virginia & 2004 & 20 & $-{ }^{\mathrm{b}}$ \\
\hline Washington & 2000 & 10 & 0.067 \\
\hline Wisconsin & 1989 & 11 & 0.074 \\
\hline
\end{tabular}

${ }^{\text {a } T h e ~ E I T C ~ p r o g r a m ~ w a s ~ e n a c t e d ~ t o o ~ r e c e n t l y ~ t o ~ c a p t u r e ~ m e a n i n g f u l ~ h e a l t h ~ o u t c o m e s . ~}$

${ }^{\mathrm{b}}$ The Behavioral Risk Factor Surveillance System data set that was used to estimate HRQL gains changed the sampling frame within the period of interest, so these states were only used in the analysis of mortality rates. Overall QALE was generated using mean HRQL effects from 22 states and mean mortality rate effects from 26 states.

${ }^{\text {C}}$ The state EITC program existed for only 2 years (between 1999 and 2001) before being re-enacted in 2013. We attempted to capture the 2 years of program effects on mortality between 1999 and 2001. EITC, earned income tax credit; HRQL, health-related quality of life; QALE, quality-adjusted life expectancy.

two analyses (HRQL and mortality rates) are not strictly comparable. Twenty-seven states have implemented a supplemental EITC policy, with states implementing these policy changes at
Mortality data were excluded for California because its EITC program was implemented in 2015, resulting in inadequate follow-up time. HRQL data were excluded for Colorado, Connecticut, Ohio, and Virginia because the survey design and sampling frame of the BRFSS were changed within the period of interest, potentially explaining any observed change in HRQL. Colorado's mortality rates are also potentially attenuated because EITC was enacted in 1999 but withdrawn in 2001. It was re-enacted in 2013, but this date was out of the range of this analysis Table 3.

\section{Statistical Analysis}

An interrupted time series analysis was conducted using SAS, version 9.4. There were 51 states from 1993 to 2008 , yielding $51 \times 16=816$ data points, or 51 series of data, one for each state. The slope in the annual change in QALE was observed for each of the 51 states, and the annual change in QALE was observed before and after EITC implementation for 22 states for HRQL and 26 states for mortality. Thus, data were collapsed across different numbers of states, depending on the outcome measure, to compute the mean effects for each outcome measure. The mean effect of EITC implementation was estimated separately for HRQL and for mortality as follows:

Let $y_{i, t}$ be the health outcome measure for state $i$ at year $t$. Suppose binary variable $I$ is an indicator for the implementation of EITC and variable $t_{2}$ is the number of years since the implementation of EITC and $t_{2}=0$ for years before the implementation. The following model was applied:

$E\left(y_{i, t}\right)=\beta_{0 i}+\beta_{1 i t}+\beta_{2 i I}+\beta_{3 i t 2}+\beta_{4} X$,

where $X$ is a set of possible confounding variables (used only in sensitivity analyses) and $\beta j i(j=0,1,2,3)$ are the state-specific random coefficients to incorporate differences across states. To examine the impact of EITC, $\beta_{2 i}$ and $\beta_{3 i}$ were estimated for the changes on level and slope, respectively. In sum, the slope was computed for each state prior to and after implementation of EITC by examining the interaction term of EITC on each of the outcome measures of interest.

The statistical approach was validated in a number of ways. First, each of the 51 states was visually inspected for annual 
Table 3. Incremental Cost-Effectiveness $(95 \% \mathrm{Cl})$ of State Earned Income Tax Credit Supplements and Sensitivity Analyses ${ }^{2}$

\begin{tabular}{|c|c|c|c|}
\hline Analyses & $\begin{array}{l}\text { Mean cost, } \\
\$(95 \% \mathrm{Cl})\end{array}$ & $\begin{array}{l}\text { Mean effectiveness } \\
\text { (QALY gained) }\end{array}$ & $\begin{array}{l}\text { Incremental cost-effectiveness } \\
\text { ratio (\$/QALY gained) }\end{array}$ \\
\hline \multicolumn{4}{|l|}{ Microsimulations } \\
\hline Average recipient $(95 \% \mathrm{Cl})$ & $16371(10058,22765)$ & $2.2(1.4,3.1)$ & $7686(4053,13392)$ \\
\hline \multicolumn{4}{|l|}{ Family size $(95 \% \mathrm{Cl})$} \\
\hline No children & $3298(2001,4579)$ & 1.6 & $2107(1279,2925)$ \\
\hline 1 child & $21963(13401,30574)$ & 2.0 & $11054(6745,15389)$ \\
\hline 2 children & $36182(22206,50363)$ & 2.2 & $16404(10068,22834)$ \\
\hline 3 children & $40865(25031,56496)$ & 2.9 & $14261(8735,19716)$ \\
\hline \multicolumn{4}{|l|}{ One-way sensitivity analyses ${ }^{b}$} \\
\hline \multicolumn{4}{|l|}{ Deadweight loss } \\
\hline $15 \%$ & 16189 & 2.2 & 7666 \\
\hline $45 \%$ & 24311 & 2.2 & 11530 \\
\hline \multicolumn{4}{|l|}{ Discount rate } \\
\hline $0 \%$ & 27388 & 3.7 & 7732 \\
\hline $5 \%$ & 12187 & 1.6 & 7675 \\
\hline
\end{tabular}

${ }^{\text {a }}$ The incremental cost-effectiveness ratio represents the change in costs divided by the change in QALYs gained among states that supplemented the EITC relative to states that did not supplement the EITC. All analyses are discounted at $3 \%$ unless otherwise indicated. By convention, all effectiveness values are rounded to the nearest 0.1 decimal place.

${ }^{b}$ Based on the average micro-simulation model.

EITC, earned income tax credit; QALYs, quality-adjusted life-years.

changes in QALE between 1980 and 2011 (Appendix [available online] shows a complete list of states.) Table 2 in this paper shows changes in QALE by state prior to and after implementation of the EITC (by the year enacted) for those states that adopted EITC. In this table, the change in slope of QALE after enactment of EITC was positive in the vast majority of states that adopted supplemental EITC. Adopting states that had negative slopes tended to have relatively small supplements to EITC. The marginal QALE values presented in Table 2 represent the marginal gain in QALE by state computed by obtaining the simple, undiscounted product of marginal HRQL and marginal life expectancy changes. The primary analysis estimates these values over the remaining life span of the average EITC recipient at a 3\% rate of discount.

Second, dose-response effects were estimated by ordinary least squares analysis to ensure that higher state-level supplements were associated with the outcomes of interest. Similarly, an analysis of the association between family size and health effects was modeled. This analysis not only provides policymakers with information on the differential impacts of EITC supplementation by family size, but also serves to validate the model because larger families receive disproportionately large EITC supplements.

\section{Markov Model}

A simple microsimulation model was built using 10,000 random walk trials (model finalized November 11, 2015). In the control arm, the status quo (baseline receipt of federal EITC) was estimated by exposing each hypothetical participant to their agespecific probability of death during each 1-year cycle in the model as derived from an unabridged U.S. life table. ${ }^{34}$ Participants who "died," exited the model and participants who "survived" exposure to this probability of death remained in the model. This approach was validated using the life table approach. ${ }^{35}$

In the supplemental EITC arm, the model also accounted for annual losses associated with transfers of cash from better-off groups to the poor (deadweight loss) ${ }^{27}$ and annual incremental changes in QALE associated with EITC supplementation. Changes in healthcare utilization were not estimated. The inclusion of healthcare system costs may alter the social costs of EITC (either increasing them or decreasing them).

Even after accounting for years in which recipients are ineligible, recipients who do not file for EITC, and discounting, the very small annual increases in QALE among states that implement EITC can become substantial. This is because these effects are calculated from the time of EITC receipt until death for the average recipient.

Payments to EITC recipients are known with relative precision and accuracy (as they are based on Internal Revenue Service claims), as are age-specific probabilities of mortality from age 25 years (the age at which EITC starts for most recipients) through age 65 years (as they are based on all deaths in the U.S.). Therefore, the most likely sources of significant error in the model are estimates of deadweight loss (non-random) and QALE (based upon sampling error in the BRFSS and state-to-state variability for EITC expansion states). To test the sensitivity of the assumptions presented here, deadweight loss error was modeled using a triangular distribution with a mean of $30 \%$ and endpoints at $15 \%$ and $45 \%$ to ensure a wide range of plausible values. The observed random error associated with or state-level analyses for 